\title{
Outcomes of surgical treatment of diabetic foot osteomyelitis: a series of 185 patients with histopathological confirmation of bone involvement
}

\author{
F. J. Aragón-Sánchez • J. J. Cabrera-Galván • \\ Y. Quintana-Marrero • M. J. Hernández-Herrero • \\ J. L. Lázaro-Martínez • E. García-Morales • \\ J. V. Beneit-Montesinos • D. G. Armstrong
}

Received: 15 April 2008 / Accepted: 25 July 2008 / Published online: 22 August 2008

(C) Springer-Verlag 2008

\begin{abstract}
Aims/hypothesis We analysed the factors that determine the outcomes of surgical treatment of osteomyelitis of the foot in diabetic patients given early surgical treatment within $12 \mathrm{~h}$ of admission and treated with prioritisation of footsparing surgery and avoidance of amputation.

Methods A consecutive series of 185 diabetic patients with foot osteomyelitis and histopathological confirmation of bone involvement were followed until healing, amputation or death.

Results Probing to bone was positive in 175 cases $(94.5 \%)$ and radiological signs of osteomyelitis were found in 157 cases (84.8\%). Staphylococcus aureus was the organism isolated in the majority of cultures $(51.3 \%)$, and in 35 cases $(36.8 \%)$ it proved to be methicillin-resistant. The surgical treatment performed included 91 conservative surgical
\end{abstract}

F. J. Aragón-Sánchez · J. J. Cabrera-Galván •

Y. Quintana-Marrero • M. J. Hernández-Herrero

Diabetic Foot Unit, La Paloma Hospital,

Las Palmas de Gran Canaria, Spain

J. L. Lázaro-Martínez • E. García-Morales •

J. V. Beneit-Montesinos

Diabetic Foot Unit, Complutense University Clinic,

Madrid, Spain

D. G. Armstrong

Scholl's Center for Lower Extremity Ambulatory

Research (CLEAR) at Rosalind Franklin University

of Medicine and Science,

Chicago, IL, USA

F. J. Aragón-Sánchez $(\bowtie)$

Diabetic Foot Unit, Hospital La Paloma,

C/Maestro valle 20,

35005 Las Palmas de Gran Canaria, Canary Islands, Spain

e-mail: javiaragon@telefonica.net procedures, which were defined as those where no amputation of any part of the foot was undertaken (49.1\%). A total of 94 patients received some degree of amputation, consisting of 79 foot-level (minor) amputations (42.4\%) and 15 major amputations (8\%). Five patients died during the perioperative period (2.7\%). Histopathological analysis revealed 94 cases (50.8\%) of acute osteomyelitis, 43 cases $(23.2 \%)$ of chronic osteomyelitis, 45 cases $(24.3 \%)$ of acute exacerbation of chronic osteomyelitis and three remaining cases (1.6\%) designated as 'other'. The risks of failure in the case of conservative surgery were exposed bone, the presence of ischaemia and necrotising soft tissue infection.

Conclusions/interpretation Conservative surgery without local or high-level amputation is successful in almost half of the cases of diabetic foot osteomyelitis. Prospective trials should be undertaken to determine the relative roles of conservative surgery versus other approaches.

Keywords Bone infection - Diabetic foot .

Diabetic foot infections · Foot ulcer - Necrotising .

Necrotizing · Osteomyelitis

\begin{abstract}
Abbreviation
NSTI necrotising soft tissue infection
\end{abstract}

\section{Introduction}

Osteomyelitis is one of the most frequent complications of diabetic foot ulcers, amounting to $10-15 \%$ of mild infections and almost $50 \%$ of severe infections [1]. Despite its high frequency, the treatment of osteomyelitis of the foot in diabetic patients continues to spur debate and so far optimal treatment is yet to be defined [1-3]. The different 
tendencies in the treatment of osteomyelitis of the foot in diabetic patients can be defined as conservative, treatment by antibiotics or surgical. The problem lies in the fact that some of these conservative medical approaches include 'limited debridement', which increases confusion as this is essentially surgical treatment too, and often the type of surgery performed on the bone is not clearly defined. In our view, the term 'debridement' should be used when referring to the removal of infected, devitalised or necrotic skin or soft tissue, but when referring to surgery performed on infected bones, more accurate terms should be used to make it possible to establish comparisons between the results of the different working groups. On the other hand, patients undergoing surgical treatment are also treated with antibiotic therapy, with variable postoperative periods and patterns. Another problem many series pose is the fact that the diagnosis of osteomyelitis is done on the basis of different clinical and radiological tests, but not confirmed on what is regarded as the gold standard for diagnosing osteomyelitis, namely histopathological study of bone involvement.

Because of these issues, we know little about infected bone histopathology in patients with diabetic foot complications. There is currently a tendency to define these processes as 'chronic osteomyelitis', while not knowing exactly the type of inflammatory infiltration occurring in the bone. It is known that both the behaviour and prognosis of patients with osteomyelitis are different depending on whether osteomyelitis, soft tissue infection or a combined infection are involved [4], but we do not know whether the histopathological type of osteomyelitis depends on an association with soft tissue infection and whether this has any influence on treatment or prognosis. The philosophical basis of the treatment for osteomyelitis of the foot in people with diabetes to which we subscribe involves early surgical treatment prioritising preservation and an attempt to avoid amputation so as not to alter the foot's biomechanics. This is followed by postoperative bone-culture-directed antibiotic therapy. To our knowledge, there are no reports in the medical literature on outcomes of this type of care in a cohort of patients consisting entirely of histopathologically confirmed cases of osteomyelitis. Here, we present the results of surgical treatment of osteomyelitis of the foot in a consecutive series of 185 diabetic patients with histopathological confirmation of bone involvement. We also analyse the factors that have an influence on the failure of conservative surgery.

\section{Methods}

We abstracted data from 498 consecutive patients with diabetic foot ulcers treated in the Diabetic Foot Unit of La Paloma Hospital as inpatients or outpatients from 1 October
2002 to 31 October 2007. Of these, 292 patients suffered from infection, and among this group we studied 185 patients with osteomyelitis. Many of the patients had been previously managed by other clinical teams using other approaches, including antibiotics. All patients included in this study gave written informed consent prior to surgical treatment.

The infection diagnosis was established on the basis of the presence of purulent secretion and/or two signs and symptoms of inflammation: induration, erythema, pain, raised temperature, lymphangitis, fetid odour or gas formation [5]. Patients treated for dry necrosis as the first lesion and who became secondarily infected were excluded, We defined 'primary infection' as when the infection was responsible for all the tissue damage and was prior to necrotic changes. Cellulitis was defined as skin and subcutaneous cell tissue infections, with no soft tissue necrosis. In cases of bone infection associated with soft tissue infection, we excluded cellulitis, since the latter will be practically constant as a reaction of soft tissue to bone infection.

Abscesses are purulent collections in any compartment of the foot. The diagnosis of necrotising soft tissue infection (NSTI) was established if necrosis of the skin or other tissue planes was found during initial examination or if soft tissue necrosis was found during surgical intervention. We classified NSTIs as necrotising cellulitis if they affected subcutaneous tissue and the skin, as necrotising fasciitis if they affected the deep fascia and the tissues located above, and as myonecrosis in cases where muscular necrosis was present. The preoperative diagnosis of osteomyelitis was performed on the basis of a combination of probe-to-bone test through the ulcer and a radiological study of the foot. When no radiological changes were present, and the bone was exposed or probed, the patient was operated on. We excluded one case of septic arthritis from this study. Osteomyelitis location in the forefoot included the metatarsal heads and their distal region; locations in the midfoot included the region from metatarsal neck toes Chopart's joint; and those in the hindfoot included the area from Chopart's joint to ankle. Lower limb ischaemia was diagnosed if any of the following criteria were met: absence of both distal pulses, an ankle/ arm index below 0.9 or transcutaneous oxygen pressure of less than $30 \mathrm{mmHg}$. The neurological examination was undertaken using Semmes-Weinstein filaments $(5.07=$ 10 g) (Novalab ibérica, Alcalá de Henares, Madrid, Spain). The test was conducted at six plantar sites on the forefoot (big toe, third and fifth toes, and the metatarsal heads of the first, third and fifth ray), two in midfoot and one in the heel. We defined neuropathy as three or more sites insensate to test stimulus. Leucocytosis was defined as leucocyte count $>11 \times 10^{9} / 1$. Thrombocytosis was defined as a platelet count higher than $450 \times 10^{9} / 1$. All patients were operated on within the first $12 \mathrm{~h}$ after admission to our unit. 
We defined debridement as the removal of devitalised, infected and/or necrotised soft tissue. Conservative surgery (Table 1) was defined as procedures in which only infected bone and non-viable soft tissue were removed, but no amputation of any part of the foot was undertaken. Conservative surgery conserved more distal tissue. Minor amputations were defined as procedures involving a partial amputation of the foot, including bone and soft tissue distal to infected bone, but not involving the ankle joint. Major amputations were those performed proximal to the ankle. Failure of conservative surgery was defined as the need to perform any amputation of the foot in two settings: (1) impossibility to perform a conservative procedure during initial operation; or (2) the need to perform any amputation later than an initially conservative surgical procedure.

During surgical intervention, samples were extracted from the affected bone for analysis by microbiological and pathological laboratories. Microbiological data were lost in nine patients. Surgical wounds were left open and packed with gauze soaked in hydrogen peroxide or calcium alginate. Patients were asked about prior admissions for previous antibiotic treatment. All patients were given an initial empirical antibiotic treatment with ampicillin/sulbactam except in cases of associated allergy. The first dose of ampicillin/sulbactam ( $2 \mathrm{~g})$ was administered during anaesthesia induction. When cultures and antibiograms were available, antibiotic course was modified according the results. Postoperative antibiotic treatment was very variable. Generally, when the wound was totally occupied by granulation tissue and the operated bone was not exposed, antibiotic treatment was discontinued.

Repeat surgery was performed when necessary to control infection. Wounds were left open to healing by second intention. Surgical wounds for major amputations were closed. Wound management varied up until January 2004. From that date biocide charcoal dressings with silver were systematically used (Actisorb plus 25; Johnson and Johnson Wound Management, Somerville, NJ, USA). Perioperative mortality was defined as death occurring within 30 days after operation. Healing was defined as complete epitheli- sation of the ulcer and/or the surgical wound performed to operate the bone infection. All patients were monitored until their wounds healed, except for nine patients who were lost to follow-up and three patients whose wounds had not healed at the end of study.

For the calculation of healing time we excluded patients with major amputations because their wounds were closed during surgery. Histopathological findings in bone specimens were defined as acute osteomyelitis when necrosis, destroyed bone and infiltrations of polymorphonuclear granulocytes at cortical sites and inside the bone marrow were present. Congestion or thrombosis of medullary or periosteal small vessels was also a frequent finding. It was defined as chronic osteomyelitis when there was destroyed bone and infiltrations of lymphocytes, histiocytes and/or plasmatic cells at cortical sites and inside the bone marrow. It was defined as acute exacerbation of chronic osteomyelitis when there was a background of chronic osteomyelitis, upon which infiltration of polymorphonuclear granulocytes was imposed. All three cases of osteomyelitis exhibited areas of fibrosis in variable forms and medullar oedema.

Discrete variables were compared using the $\chi^{2}$ test and in the case of two independent samples the median comparison was performed using Mann-Whitney $U$ test. In the case of three independent samples, non-parametric statistical analysis was performed using Kruskal-Wallis ANOVA by ranks test. The patients were divided into two groups: patients subject to conservative surgery and patients who required some form of amputation. Univariate analysis was undertaken with a level of statistical significance set at $p<0.05$. Later, variables that reached statistical significance were introduced in a stepwise logistic regression analysis using Statplus statistical analysis software (AnalystSoft, Vancouver, British Columbia, Canada).

\section{Results}

Of the 498 patients consecutively evaluated in this study, 292 were treated for infection, which amounted to $58.6 \%$ of

Table 1 Types of conservative surgeries performed in this series

\begin{tabular}{|c|c|c|c|}
\hline Conservative surgery & Definition & $n$ & Percentage \\
\hline Ostectomy & Any removing of bone tissue without formal anatomical limits & 30 & 32.96 \\
\hline Metatarsal head resection & Removal of metatarsal head & 24 & 26.37 \\
\hline Distal phalangectomy & Removal of any part (or all) of distal phalanx & 10 & 10.98 \\
\hline Interphalangeal joint resection & Removal of any interphalangeal joint & 8 & 8.79 \\
\hline Metatarsal resection & Removal of any part of metatarsal bone excluding head & 6 & 6.59 \\
\hline Metatarso-phalangeal joint resection & Removal of metatarso-phalangeal joint & 4 & 4.39 \\
\hline Sesamoidectomy & Removal of one or both sesamoid bones & 5 & 5.49 \\
\hline Partial calcanectomy & Removal of a partial amount of calcaneal bone & 2 & 2.19 \\
\hline Exostectomy & Total or partial removal of exostosis & 2 & 2.19 \\
\hline
\end{tabular}


all cases. Of the patients admitted with infection, $256(88 \%)$ were admitted with primary infection and the remaining 36 $(12 \%)$ suffered from necrosis with secondary infection. The types of infection were soft tissue infections in 70 cases $(27.3 \%)$, osteoarticular infection in 130 cases $(50.8 \%)$ and combined infections in 56 cases (21.9\%). Demographic and clinical characteristics of the study population are shown in Table 2. Osteomyelitis was associated with different types of soft tissue infections, but it was more frequent $(68.8 \%)$ as isolated bone infection (Table 3). Laboratory finding are shown in Table 4. White blood cells, leucocytosis and platelet count were significantly higher in the group where osteomyelitis was associated with soft tissue infections. An ulcer was the infection's point of entry in 170 cases $(91.8 \%)$, whereas in the remaining cases it was perforating injuries. The average ulcer duration was 113 days (SD 264) and the average duration of septic signs was 51 days (SD 111.2). Lower limb ischaemia was detected in 119 patients (64.3\%) and peripheral neuropathy in 163 patients (88.1\%).

Osteomyelitis was located in the forefoot in $90 \%$ of cases, in the midfoot in 5\% and in the hindfoot in another $5 \%$ of cases. The bone was visible at the bottom of the lesion in 58 cases $(31.3 \%)$ and probing to bone was positive in 175 cases $(94.6 \%)$. In ten cases the bone could not be probed through the wound, but there were radiological signs of osteomyelitis in eight of these. Simple x-rays of the foot revealed radiological changes compatible with osteomyelitis in 157 cases $(84.8 \%)$, with 28 cases $(15.1 \%)$ showing no radiological changes. In these 28 cases, the bone was visible in ten and in 26 probing to bone was positive and was the only diagnostic tool. Postoperative cultures performed on these 28 cases were positive in 25

Table 2 Demographic and clinical characteristics of the study population

\begin{tabular}{|c|c|}
\hline Characteristic & Value \\
\hline Age, years, mean (SD) & $64.7(11.8)$ \\
\hline Men $(\%)$ & 62.7 \\
\hline Women $(\%)$ & 37.3 \\
\hline Type 2 diabetes vs type $1(\%)$ & 98.3 \\
\hline Diabetes duration, years, mean (SD) & $17.1(9)$ \\
\hline Insulin treatment $(\%)$ & 63.1 \\
\hline Tobacco, current or previous user (\%) & 29.1 \\
\hline Heart disease $(\%)^{\mathrm{a}}$ & 34 \\
\hline Nephropathy $(\%)^{\mathrm{a}}$ & 14 \\
\hline Retinopathy $(\%)^{\mathrm{a}}$ & 62.1 \\
\hline Neuropathy $(\%)^{\mathrm{a}}$ & 25.9 \\
\hline Limb ischaemia $(\%)^{\mathrm{a}}$ & 19.4 \\
\hline Stroke $(\%)^{\mathrm{a}}$ & 10.8 \\
\hline Dyslipidaemia $(\%)^{\mathrm{a}}$ & 32.9 \\
\hline Previous ulceration (\%) & 49.7 \\
\hline Previous amputation (\%) & 34.5 \\
\hline
\end{tabular}

${ }^{\text {a }}$ As stated in medical records
Table 3 Clinical presentation of bone infection

\begin{tabular}{lcc}
\hline Infection type & \multicolumn{2}{c}{ Patients per type } \\
\cline { 2 - 3 } & $n$ & Percentage \\
\hline Septic arthritis & 1 & 0.5 \\
Osteitis & 1 & 0.5 \\
Osteitis + abscess & 1 & 0.5 \\
Osteomyelitis & 128 & 68.8 \\
Osteomyelitis + abscess & 13 & 6.9 \\
Osteomyelitis + necrotising cellulitis & 33 & 17.7 \\
Osteomyelitis + necrotising fasciitis & 5 & 2.6 \\
Osteomyelitis + myonecrosis & 4 & 2.1 \\
Total & 186 & 100 \\
\hline
\end{tabular}

cases, with osteomyelitis confirmed by pathological analysis in all cases except one, for which the sample was not representative. Antibiotic treatment prior to admission had been given to 132 patients $(71.35 \%)$, but we have no data about treatment duration or dosage.

The definitive surgical treatment performed included 91 conservative surgical procedures (49.2\%) shown in Table 1 . A total of 94 patients received some degree of amputation, 79 minor amputations (42.7\%) and 15 major amputations (8\%). Minor amputations consisted of 70 partial or total amputations of toes and nine open transmetatarsal amputations combined with delayed secondary closure. Successful conservative surgery was more frequent in patients with isolated bone infection $(p=0)$ and any type of amputation was more frequent when soft tissue infection was present $(p=0.0005)$. The sequence of surgical treatment is shown in Fig. 1. Among the patients subjected to successful conservative surgery $(n=91), 72(79.1 \%)$ were also subjected to soft tissue debridement and $20.9 \%$ were subjected to bone surgery only. In this group, ten patients $(10.9 \%)$ were

Table 4 Laboratory results according to clinical presentation

\begin{tabular}{llll}
\hline Parameter $^{\mathrm{a}}$ & $\begin{array}{l}\text { Osteomyelitis } \\
(n=129)\end{array}$ & $\begin{array}{l}\text { Osteomyelitis }+ \\
\text { soft tissue } \\
\text { infection }(n=56)\end{array}$ & $\begin{array}{l}p \\
\text { value }\end{array}$ \\
\hline Glucose $(\mathrm{mmol} / \mathrm{l})$ & 9.7 & 11.2 & 0.177 \\
BUN $(\mathrm{mmol} / \mathrm{l})$ & 18.9 & 16.7 & 0.427 \\
Creatinine $(\mu \mathrm{mol} / \mathrm{l})$ & 106 & 97.2 & 0.545 \\
White blood cell & $8.5 \times 10^{9}$ & $12.07 \times 10^{9}$ & 0.000 \\
count $(/ \mathrm{l})$ & & & \\
Leucocytosis $(\%)$ & 31 & 64.2 & 0.000 \\
$\begin{array}{l}\text { Platelet count }(/ 1) \\
\text { Thrombocytosis }(\%)\end{array}$ & $273 \times 10^{9}$ & $326 \times 10^{9}$ & 0.001 \\
$\begin{array}{l}\text { Glycated haemoglobin } \\
\text { (proportion of total }\end{array}$ & 0.079 & 17.3 & 0.138 \\
haemoglobin) & & 0.089 & 0.338 \\
\end{tabular}

${ }^{a}$ Values are expressed as median unless otherwise indicated BUN, blood urea nitrogen 
Fig. 1 The sequence of surgical treatment and numbers treated

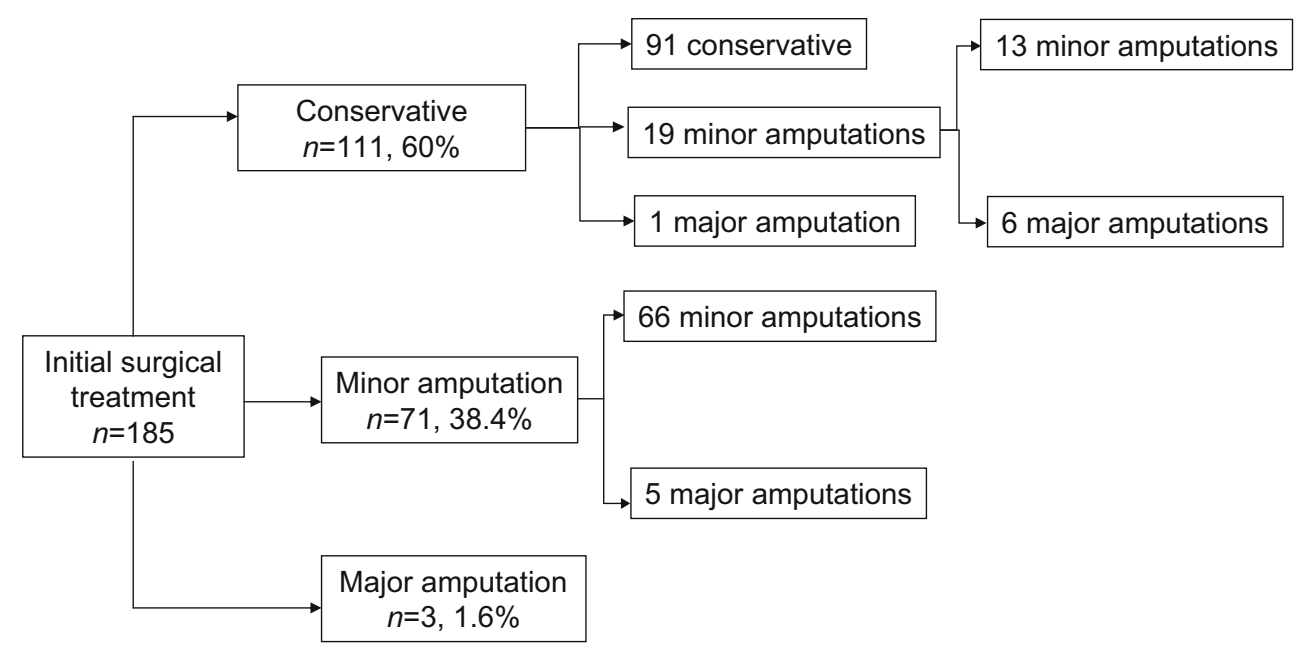

subjected to more than one intervention, with an average of 2.3 surgical interventions per patient (SD 0.94). In the case of patients subjected to minor amputations as later successful treatment, $27(33.7 \%)$ were operated on more than once, with an average of 2.6 interventions per patient (SD 1.0). Major amputation included ten below-the-knee and five above-the-knee amputations and was the initial surgical treatment for three patients. Major amputations were preceded by one or more conservative or minor amputation surgical procedures in 12 cases, with an average of 4.1 interventions per patient (SD 2.1). Perioperative mortality rate was $2.7 \%(n=5)$.

The microbiological aetiology of osteomyelitis in bone specimens is show in Table 5. One organism was isolated in 108 specimens and two organisms in 46 specimens. None were isolated in 20 specimens. Negative cultures were not related to previous antibiotic treatment $\left(\chi^{2}\right.$ test $2.09, d f=1$, $p=0.14$ ). Staphylococcus aureus was the most frequently isolated organism as the cause of the osteomyelitis (47.5\%) and was the only bacterium isolated on 61 occasions $(64.2 \%)$; on 34 occasions $(35.7 \%)$ it was associated with other organisms. In 35 cases (36.8\%) it proved to be methicillinresistant. There were three cases with yeast aetiology.

Histopathological analysis revealed 94 cases $(50.8 \%)$ of acute osteomyelitis, 43 cases $(23.2 \%)$ of chronic osteomyelitis, 45 cases $(24.3 \%)$ of acute exacerbation of chronic osteomyelitis and in the three remaining cases (1.6\%) one sample was not representative enough for diagnosis, another was diagnosed as fracture callus and the last was found to have changes compatible with Charcot's neuroarthropathy. In 182 cases histopathological analysis confirmed the diagnosis. The different histopathological types of osteomyelitis were related to the white blood cell count, successful conservative surgery and minor amputations. The variables studied in different histopathological types of osteomyelitis are show in Table 6.

Univariate study of patients who had been subjected to conservative surgery and of those who had not is shown in
Table 7. Factors that showed significant differences between groups $(p<0.05)$ included age, ulcer duration, existence of ischaemia, soft tissue infection, necrotising soft tissue infection, white blood cell count, leucocytosis, platelet count, exposed bone, acute osteomyelitis and chronic osteomyelitis. A logistic regression model (Table 8) suggested that factors associated with amputation included

Table 5 Bacteria isolated from 176 bone cultures

\begin{tabular}{|c|c|c|}
\hline Bacterium & $n$ & $\begin{array}{l}\text { Per cent of total isolated } \\
\text { organisms }\end{array}$ \\
\hline Staphylococcus aureus & 95 & 46.5 \\
\hline $\begin{array}{l}\text { Staphylococcus } \\
\text { epidermidis }\end{array}$ & 22 & 10.7 \\
\hline Escherichia coli & 13 & 6.3 \\
\hline Enterobacter & 11 & 5.3 \\
\hline Streptococcus pyogenes & 4 & 1.9 \\
\hline Streptococcus viridans & 1 & 0.4 \\
\hline Streptococcus agalactiae & 1 & 0.4 \\
\hline $\begin{array}{l}\text { Streptococcus } \\
\text { acidominimus }\end{array}$ & 1 & 0.4 \\
\hline Enterococcus & 2 & 0.9 \\
\hline Proteus vulgaris & 4 & 1.9 \\
\hline Proteus mirabilis & 7 & 3.4 \\
\hline Proteus rettgeri & 4 & 1.9 \\
\hline Proteus morganii & 2 & 0.9 \\
\hline Klebsiella oxytoca & 2 & 0.9 \\
\hline Klebsiella pneumoniae & 1 & 0.4 \\
\hline Pseudomonas aeruginosa & 15 & 7.3 \\
\hline $\begin{array}{l}\text { Pseudomonas } \\
\text { pseudomallei }\end{array}$ & 1 & 0.4 \\
\hline Pseudomonas fluorescens & 1 & 0.4 \\
\hline Pseudomonas putrida & 1 & 0.4 \\
\hline Morganella morganii & 4 & 1.9 \\
\hline Acinetobacter & 4 & 1.9 \\
\hline Serratia & 3 & 1.4 \\
\hline Burkholderia cepacia & 1 & 0.4 \\
\hline Shigella & 1 & 0.4 \\
\hline Candida albicans & 3 & 1.4 \\
\hline
\end{tabular}


Table 6 Histopathological results in relation to clinical presentation of infection

\begin{tabular}{|c|c|c|c|c|c|}
\hline Variables & $\begin{array}{l}\text { Acute osteomyelitis } \\
(n=94)\end{array}$ & $\begin{array}{l}\text { Chronic osteomyelitis } \\
(n=43)\end{array}$ & $\begin{array}{l}\text { Acute exacerbation of } \\
\text { chronic osteomyelitis } \\
(n=45)\end{array}$ & $p$ value & $\begin{array}{l}p \text { value between } \\
\text { groups }\end{array}$ \\
\hline Median ulcer evolution (days) & 42 & 60 & 30 & 0.07 & \\
\hline Median infection evolution (days) & 15 & 30 & 20 & 0.05 & $<0.05^{\mathrm{a}}$ \\
\hline Lower limb ischaemia, $n(\%)$ & $67(71.2)$ & $22(51.1)$ & $28(62.2)$ & 0.07 & $<0.05^{\mathrm{a}}$ \\
\hline Soft tissue infection, $n(\%)$ & $31(32.9)$ & $7(16.2)$ & $17(37.7)$ & 0.06 & $<0.05^{\mathrm{a}, \mathrm{c}}$ \\
\hline Median temperature $\left({ }^{\circ} \mathrm{C}\right)$ & 36.6 & 36.5 & 36.8 & 0.31 & \\
\hline Median white blood cells count (/l) & $9.630 \times 10^{9}$ & $7.380 \times 10^{9}$ & $10.150 \times 10^{9}$ & 0.003 & $<0.05^{\mathrm{a}, \mathrm{c}}$ \\
\hline Leucocytosis, $n(\%)$ & $30(31.9)$ & $6(13.9)$ & $18(40)$ & 0.11 & $<0.05^{\mathrm{a}, \mathrm{c}}$ \\
\hline Bone exposed, $n(\%)$ & $36(38.3)$ & $9(20.9)$ & $12(26.6)$ & 0.09 & $<0.05^{\mathrm{a}}$ \\
\hline Probing to bone positive, $n(\%)$ & $92(97.8)$ & $39(90.7)$ & $40(88.8)$ & 0.08 & $<0.05^{\mathrm{b}}$ \\
\hline Skin necrosis, $n(\%)$ & $36(38.2)$ & $8(18.6)$ & $14(31.1)$ & 0.07 & $<0.05^{\mathrm{a}}$ \\
\hline $\mathrm{X}$-ray positive, $n(\%)$ & $81(86.1)$ & $38(88.3)$ & $36(80)$ & 0.5 & \\
\hline Culture positive, $n(\%)$ & $85(90.4)$ & $35(81.3)$ & $44(97.7)$ & 0.13 & $<0.05^{\mathrm{c}}$ \\
\hline Conservative surgery, $n(\%)$ & $39(41.4)$ & $31(72)$ & $21(46.6)$ & 0.002 & $<0.05^{\mathrm{a}, \mathrm{c}}$ \\
\hline Minor amputation, $n(\%)$ & $49(52.1)$ & $10(23.2)$ & $19(42.2)$ & 0.004 & $<0.05^{\mathrm{a}}$ \\
\hline Major amputation, $n(\%)$ & $6(6.3)$ & $2(4.6)$ & $5(11.1)$ & 0.46 & \\
\hline Median time in hospital (days) & 15 & 18 & 13 & 0.56 & \\
\hline Deaths, $n(\%)$ & $3(3.1)$ & $0(0)$ & $2(4.4)$ & 0.41 & \\
\hline Median time to healing (days) & 95 & 80 & 90 & 0.1 & $<0.05^{\mathrm{a}}$ \\
\hline
\end{tabular}

${ }^{a}$ For difference between acute vs chronic

${ }^{\mathrm{b}}$ For difference between acute vs acute exacerbation of chronic

${ }^{\mathrm{c}}$ For difference between chronic vs acute exacerbation of chronic

exposed bone, the presence of lower limb ischaemia and necrotising soft tissue infection.

If we exclude patients who were subjected to major amputation and/or died, we are left with 157 patients. Of these, nine were lost during the follow-up period, three currently have wounds that have not healed yet and one died after heart surgery before the surgical wound had healed. In the remaining 144 cases, wounds healed over a median period of 90 days. Median wound healing times in patients with successful conservative surgery was 80 days, (range 12-365) vs 120 days (range 21-365) in the case of minor amputations $(p=0.003)$. Median wound healing times were longer in cases with associated soft tissue infection $(p=0.0005)$ and limb ischaemia $(p=0.001)$.

\section{Discussion}

In a recent study of a cohort of 1,666 patients, osteomyelitis was diagnosed in $20 \%$ of patients who developed a foot infection [6]. In this study, osteomyelitis was present in $72.2 \%$ of the patients with foot infection, which is by far the most frequent type of infection treated in our unit. There is currently a tendency to consider that, with the new medication options, treatment by antibiotics is more feasible [2], but a review of the literature seems to indicate that antibiotics alone may not be enough. The series in which osteomyelitis was not confirmed by histopathology
[7-12] show healing rates of 53-88\% with antibiotic treatment, although in some cases 'limited' debridement was also performed. Others have also suggested that antibiotic therapy combined with debridement of the infected bone can cure most cases of diabetic foot osteomyelitis [13, 14]. Old series with treatment by antibiotics are burdened with up to $30 \%$ of below-the-knee amputations [7]; in other cases amputations or the level at which they have been performed were not recorded when conservative treatment failed [8-10].

The studies which support a surgical approach likewise did not report histopathological confirmation [15] and the results of the different surgical working groups are not well evidenced [2]. Like other authors, our group believes that osteomyelitis of the diabetic foot is, once diagnosed, predominantly a surgical disease $[15,16]$. However, surgical treatment in one of this series [15] involved major amputations in nearly $25 \%$ of cases. Only $57 \%$ of 168 patients with limb salvage had complete healing of the wounds $(82 \%$ of them remained complicated by osteomyelitis). These results are worse than the new series with a predominantly antibiotic-based treatment of osteomyelitis [11, 17]. Where possible, we defend an initial conservative surgical treatment, but the role of this approach is not yet well defined. Most series report amputation as the only possible surgical treatment [18-20]. In a surgical series, the authors performed a study of 110 patients with histopathological confirmation of osteomyelitis in $96 \%$ of cases [18]. They did not perform conservative surgery in forefoot osteomye- 
Table 7 Comparison of patients undergoing conservative surgery with those who had any amputation

\begin{tabular}{|c|c|c|c|}
\hline Variables $^{\mathrm{a}}$ & Conservative surgery $(n=91)$ & Amputation $(n=94)$ & $p$ value \\
\hline Age (years) & 63 & 68 & 0.02 \\
\hline Diabetes evolution (years) & 19 & 15 & 0.23 \\
\hline Insulin treatment, $n(\%)$ & $56(61.5)$ & $59(64.8)$ & 0.423 \\
\hline Previous ulceration, $n(\%)$ & $47(51.6)$ & $43(47.2)$ & 0.608 \\
\hline Previous amputation, $n(\%)$ & $28(30.7)$ & $34(37.3)$ & 0.282 \\
\hline Ulcer evolution (days) & 60 & 30 & 0.04 \\
\hline Infection evolution (days) & 17 & 15 & 0.08 \\
\hline Forefoot, $n(\%)$ & $80(87.9)$ & $87(92.5)$ & 0.287 \\
\hline Midfoot, $n(\%)$ & $7(7.69)$ & $2(2.1)$ & 0.079 \\
\hline Hindfoot, $n(\%)$ & $4(4.4)$ & $5(5.3)$ & 0.770 \\
\hline Lower limb ischaemia, $n(\%)$ & $42(46.1)$ & $74(81.3)$ & 0.000 \\
\hline Soft tissue infection, $n(\%)$ & $11(12)$ & $43(47.2)$ & 0.000 \\
\hline Necrotising soft tissue infection, $n(\%)$ & $4(4.4)$ & $38(40.4)$ & 0.000 \\
\hline Temperature $\left({ }^{\circ} \mathrm{C}\right)$ & 36.6 & 36.7 & 0.43 \\
\hline Glucose $(\mathrm{mmol} / \mathrm{l})$ & 10.4 & 9.9 & 0.18 \\
\hline BUN (mmol/l) & 17.3 & 18.5 & 0.56 \\
\hline Creatinine $(\mu \mathrm{mol} / \mathrm{l})$ & 97.2 & 106 & 0.28 \\
\hline Glycated haemoglobin & 0.082 & 0.084 & 0.82 \\
\hline White blood cell count $(/ 1)$ & $8.315 \times 10^{9}$ & $10.6 \times 10^{9}$ & 0.00 \\
\hline Leucocytosis, $n(\%)$ & $27(29.6)$ & $49(52.13)$ & 0.002 \\
\hline Platelet count $(/ 1)$ & $266.5 \times 10^{9}$ & $308 \times 10^{9}$ & 0.039 \\
\hline Bone exposed, $n(\%)$ & $14(15.3)$ & $42(46.1)$ & 0.007 \\
\hline Probing to bone positive, $n(\%)$ & $86(94.5)$ & $87(95.6)$ & 0.958 \\
\hline $\mathrm{X}$-ray positive, $n(\%)$ & $81(89)$ & $73(80.2)$ & 0.122 \\
\hline MRSA, $n(\%)$ & $16(17.5)$ & $19(20.8)$ & 0.648 \\
\hline Acute osteomyelitis, $n(\%)$ & $38(41.7)$ & $55(60.4)$ & 0.015 \\
\hline Chronic osteomyelitis, $n(\%)$ & $69(34)$ & $12(13.1)$ & 0.001 \\
\hline Chronic-acute osteomyelitis, $n(\%)$ & $21(23)$ & $22(24.1)$ & 0.697 \\
\hline Hospital stay (days) & 14 & 15 & 0.38 \\
\hline Death, $n(\%)$ & $2(2.2)$ & $3(3.3)$ & 0.677 \\
\hline
\end{tabular}

${ }^{a}$ Values are expressed as median unless otherwise indicated

BUN, blood urea nitrogen; MRSA, methicillin-resistant Staphylococcus aureus

litis, but in our experience, conservative surgery was successful in $48 \%$ of such patients.

Other authors retrospectively compared results in the treatment of osteomyelitis without ischaemia over two different periods [21]. One group of 32 patients belonged to a historical group (1986-1993) of patients treated with antibiotic therapy, offloading and local wound care. The second group consisted of 32 patients subjected to the same treatment and, additionally, to conservative surgery (September 1993 to March 1995). Healing rates were 57\% in the group subjected to antibiotic-based treatment and $78 \%$ in those who underwent surgery $(p<0.008)$; there was also a significant difference in healing time: $462 \pm 98$ days compared with $181 \pm 30$ days $(p<0.008)$. These authors concluded that, in the case of osteomyelitis of the foot in diabetic patients, conservative surgery reduced healing time, the duration of antibiotic therapy and the number of secondary surgical procedures [21]. The contribution of surgery to the treatment of patients with osteomyelitis was shown in a series of 157 patients with complicated ulcers [22]. Of these,
45 patients had osteomyelitis without ischaemia and 41 of them (91\%) underwent surgery, conservative surgery in 28 $(68 \%)$ cases and minor amputations in $13(32 \%)$ cases. In our series, only 66 (35.6\%) patients suffered from osteomyelitis without ischaemia. We performed 49 conservative

Table 8 Logistic regression model

\begin{tabular}{lccc}
\hline Variables & $p$ value & Odds ratio & $95 \%$ CI \\
\hline Age & 0.7993 & 1 & $0.9-1.0$ \\
Ulcer evolution & 0.2376 & 0.9 & $0.9-1.0$ \\
Bone exposed & 0.0000 & 7.7 & $2.9-20.3$ \\
Lower limb ischaemia & 0.0025 & 4.9 & $1.7-13.8$ \\
Soft tissue infection & 0.8618 & 1.1 & $0.2-5.3$ \\
Necrotising soft tissue infection & 0.0252 & 8.2 & $1.3-52.4$ \\
Platelet count & 0.5233 & 1 & $1.0-1.0$ \\
White blood cell count & 0.0534 & 1 & $1.0-1.0$ \\
Leucocytosis & 0.3240 & 0.4 & $0.1-2.1$ \\
Acute osteomyelitis & 0.7142 & 0.8 & $0.2-2.3$ \\
Chronic osteomyelitis & 0.1959 & 0.4 & $0.1-1.5$ \\
\hline
\end{tabular}


surgical procedures (74.2\%), 14 minor amputations (21.2\%) and three major amputations $(4.5 \%)$. In the three patients undergoing major amputation, two had presented with associated necrotising soft tissue infections and one had presented with Charcot's foot in an acute phase with externalised bone and abscess.

Recently, a multicentre retrospective series was published [23] of non-surgical treatment of osteomyelitis in feet without ischaemia or gangrene and without bone fragmentation in x-ray. These authors showed $64 \%$ remission with antibiotic alone in this highly selected series. We believe that inclusion of only patients without ischaemia and/or gangrene, as in these studies, provides an unrealistic view of the problem. In our series, $64.3 \%$ of patients suffered from osteomyelitis in an ischaemic foot. Another recent paper reported an apparent remission in $82.3 \%$ patients without surgery [17]. Bone biopsy was not performed but the authors did not exclude ischaemic or elderly patients, thus allowing a complete perspective of the problem. They reported a $9 \%$ rate of major amputations, similar to our series $(8 \%)$.

The most important concern about results of treatment of osteomyelitis by different working groups is the endpoint of the studies. Recent series about antibiotic-based treatment defined remission as absence of any sign of infection at the initial or contiguous site [23] or patient survival with limb intact [17]. Another used the term 'healed' with caution because of the potential for osteomyelitis relapse after therapy [11]. Surgery-based series [15] had a high rate of non-healing lesions complicated as a result of osteomyelitis. We believe that the endpoint in diabetic foot ulcers complicated by osteomyelitis must to be complete healing of the ulcer or surgical wound performed to treat the bone infection. When patients are given a course of antibiotics, there is a remission of inflammatory signs, but the ulcer remains open. The remission of infectious signs and symptoms do not represent a cure of diabetic foot osteomyelitis, because the sinus track to the bone could remain open and may act as point of entry for a new deep infection, including limb- or life-threatening infection. When the bone infection is really cured (by antibiotic or surgical treatment), the ulcer always closes. Osteomyelitis is an important cause of hard-to-heal diabetic foot ulcers. Our results show that wounds healed over a median period of 90 days. Longer time of healing was related to associated soft tissue infections, limb ischaemia and non-successful conservative surgical approach.

We have found, like others [4], that osteomyelitis has different characteristics and prognosis if combined with a soft tissue infection. Our patients with combined infections had higher white blood cell counts, platelet counts and leucocytosis rate. They suffered more amputations than the patients with osteomyelitis only. We have not demonstrated a statistical relation between type of osteomyelitis and soft tissue infection. A novelty introduced in our work is the fact that we undertook a histopathological study of all cases and found three types of osteomyelitis in the diabetic foot: acute, chronic and acute exacerbation of chronic osteomyelitis. An interesting finding in our work is one case of acute Charcot's foot. It is very difficult to gain experience of histopathological changes typical of Charcot's foot because, when neuroarthropathy is in the acute phase, an open biopsy is not indicated. We had the opportunity to perform an open biopsy, due to a diagnostic error by another centre. The clinical course of this patient was confounded with 'lymphoedema'. Walking and weight bearing was permitted over the neuroarthropathic foot. When the patient was admitted, the foot was grossly deformed and infected with an open wound. Through the wound we removed a fragment of talar bone. The pathological report stated: 'cortical fracture with remodelling and reabsortive changes. Posttraumatic bone necrolysis with slight inflammatory changes. No bone marrow inflammatory infiltration. Medullar fibrosis.' These changes were not compatible with osteomyelitis, being, rather, typical of acute fractures. This point is consistent with a recent review of diabetic foot neuroarthropathy [24]. A study on bone histomorphology showed several pathological findings but did not describe in detail the type of inflammation seen in the 29 cases of osteomyelitis [25]. Other authors studied the correlation between bone histopathology and magnetic resonance imaging in 13 patients [26]. They described three types of osteomyelitis (21 cases) in their 57 bone specimens. These pathological reports are very similar to our results, assuming that the terms 'acute and chronic' correspond to our term 'exacerbation of chronic osteomyelitis'. Distribution of pathological findings was: seven cases of acute (33.3\%), 11 cases of 'acute and chronic' $(52.3 \%)$ and three cases $(14.2 \%)$ of chronic osteomyelitis. We found acute osteomyelitis to be the most frequent type.

Univariate analysis showed that acute osteomyelitis was more common among patients who underwent amputation ( $p$ $=0.015)$, chronic osteomyelitis was more frequent among those undergoing conservative surgery $(p=0.001)$ and acute exacerbation of chronic osteomyelitis was equally common in both groups. However, in multivariate analysis, the histopathological type of osteomyelitis did not behave as a predictive factor of the risk of failure of conservative surgery. The only factors that worked as predictors of failure in the case of conservative surgery were exposed bone, the presence of arterial ischaemia and the presence of a necrotising soft tissue infection. Although our study did not have a control group, we have presented our results for surgical treatment of osteomyelitis in the context of other acceptable results and comparable-to-best series. We think that prospective trials should be undertaken to determine the relative roles of conservative surgery vs other approaches. 
Duality of interest The authors declare that there is no duality of interest associated with this manuscript.

\section{References}

1. Lipsky BA, Berendt AR, Deery HG et al (2004) Infectious Diseases Society of America: diagnosis and treatment of diabetic foot infections. Clin Infect Dis 39:885-910

2. Jeffcoate WJ, Lipsky BA (2004) Controversies in diagnosing and managing osteomyelitis of the foot in diabetes. Clin Infect Dis 39 (Suppl 2):S115-S122

3. Snyder RJ, Cohen MM, Sun C, Livingston J (2001) Osteomyelitis in the diabetic patient: diagnosis and treatment. Part 2: medical, surgical, and alternative treatments. Ostomy Wound Manage 47:24-30

4. Eneroth M, Larsson J, Apelqvist J (1999) Deep foot infections in patients with diabetes and foot ulcer: an entity with different characteristics, treatments, and prognosis. J Diabetes Complications 13:254-263

5. Lipsky BA (2004) A report from the international consensus on diagnosing and treating the infected diabetic foot. Diabetes Metab Res Rev 20(Suppl 1):S68-S77

6. Lavery LA, Armstrong DG, Peters EJ, Lipsky BA (2007) Probeto-bone test for diagnosing diabetic foot osteomyelitis: reliable or relic? Diabetes Care 30:270-274

7. Bamberger DM, Daus GP, Gerding DN (1987) Osteomyelitis in the feet of diabetic patients. Am J Med 83:653-659

8. Nix DE, Cumbo TJ, Kuritzky P, DeVito JM, Schentag JJ (1987) Oral ciprofloxacin in the treatment of serious soft tissue and bone infections: efficacy, safety and pharmacokinetics. Am J Med 82 (Suppl 4A):146-215

9. Peterson LR, Lissack LM, Canter K, Fasching CE, Clabots C, Gerding DN (1989) Therapy of lower extremity infections with ciprofloxacin in patients with diabetes mellitus, peripheral vascular disease or both. Am J Med 86:801-807

10. Pittet D, Wyssa B, Herter-Clavel C, Kursteiner K, Vaucher J, Lew PD (1999) Outcome of diabetic foot infections treated conservatively: a retrospective cohort study with long-term follow-up. Arch Intern Med 159:851-856

11. Embil JM, Rose G, Trepman E et al (2006) Oral antimicrobial therapy for diabetic foot osteomyelitis. Foot Ankle Int 27:771-779

12. Senneville E, Yazdanpanah Y, Cazaubiel M et al (2001) Rifampicin-ofloxacin oral regimen for the treatment of mild to moderate diabetic foot osteomyelitis. J Antimicrob Chemother 48:927-930

13. Grayson ML, Gibbons GW, Habershaw GM et al (1994) Use of ampicillin/sulbactam versus imipenem/cilastatin in the treatment of limb-threatening infections in diabetic patients. Clin Infect Dis 18:683-693

14. Venkatesan P, Lawn S, Macfarlane RM, Fletcher EM, Finch RG, Jeffcoate WJ (1997) Conservative management of osteomyelitis in the feet of diabetic patients. Diabet Med 14:487-490

15. Henke PK, Blackburn SA, Wainess RW et al (2005) Osteomyelitis of the foot and toe in adults is a surgical disease: conservative management worsens lower extremity salvage. Ann Surg 241:885-892

16. Frykberg RG, Wittmayer B, Zgonis T (2007) Surgical management of diabetic foot infections and osteomyelitis. Clin Podiatr Med Surg 24:469-482

17. Game FL, Jeffcoate WJ (2008) Primarily non-surgical management of osteomyelitis of the foot in diabetes. Diabetologia 51:962-967

18. Karchmer AW, Gibbons GW (1994) Foot infections in diabetes. Evaluation and management. Curr Clin Top Infect Dis 14:1-22

19. Murdoch DP, Armstrong DG, Dacus JB, Laughlin TJ, Morgan CB, Lavery LA (1997) The natural history of great toe amputations. J Foot Ankle Surg 36:204-208

20. Nehler MR, Whitehill TA, Bowers SP et al (1999) Intermediate-term outcome of primary digit amputations in patients with diabetes mellitus who have forefoot sepsis requiring hospitalisation and presumed adequate circulatory status. J Vasc Surg 30:509-517

21. Ha Van G, Siney H, Danan JP, Sachon C, Grimaldi A (1996) Treatment of osteomyelitis in the diabetic foot. Contribution of conservative surgery. Diabetes Care 19:1257-1260

22. Hartemann-Heurtier A, Ha Van G, Danan JP et al (2002) Outcome of severe diabetic foot ulcers after standardised management in a specialised unit. Diabetes Metab 28:477-484

23. Senneville E, Lombart A, Beltrand E et al (2008) Outcome of diabetic foot osteomyelitis treated non-surgically: a retrospective cohort study. Diabetes Care 31:637-642

24. Chantelau E, Onvlee GJ (2006) Charcot foot in diabetes: farewell to the neurotrophic theory. Horm Metab Res 38:361-367

25. Chantelau E, Wolf A, Ozdemir S, Hachmöller A, Ramp U (2007) Bone histomorphology may be unremarkable in diabetes mellitus. Med Klin (Munich) 102:429-433

26. Craig JG, Amin MB, Wu K et al (1997) Osteomyelitis of the diabetic foot: MR imaging-pathologic correlation. Radiology 203:849-855 